\title{
Conserved Keratin Gene Clusters in Ancient Fish: an Evolutionary Seed for Terrestrial Adaptation
}

\author{
Yuki Kimura ${ }^{1}$ and Masato Nikaido*,1 \\ ${ }^{1}$ School of Life Science and Technology, Tokyo Institute of Technology \\ ${ }^{*}$ Corresponding author: E-mail: mnikaido@bio.titech.ac.jp
}

\section{Keywords:}

Gene cluster; Keratin; Vertebrate evolution; Comparative genomics; Phylogenetics; Selection analysis; Synteny analysis

\section{Highlights}

- Two major keratin clusters are conserved from sharks to terrestrial vertebrates.

- Adult epidermis-specific keratins in amphibians stem from the two major clusters.

- A novel keratin gene subcluster was found in reedfish.

- Ancestral krt18/krt8 gene sets were found in all vertebrates.

- Functional diversification signatures were found in reedfish and amphibian keratins. 


\section{Abstract}

Type I and type II keratins are subgroups of intermediate filament proteins that provide toughness to the epidermis and protect it from water loss. In terrestrial vertebrates, the keratin genes form two major clusters, clusters 1 and 2, each of which is dominated by type I and II keratin genes. By contrast, such clusters are not observed in teleost fish. Although the diversification of keratins is believed to have made a substantial contribution to terrestrial adaptation, its evolutionary process has not been clarified. Here, we performed a comprehensive genomic survey of the keratin genes of a broad range of vertebrates. As a result, we found that ancient fish lineages such as elephant shark, reedfish, spotted gar, and coelacanth share both keratin gene clusters. We also discovered an expansion of keratin genes that form a novel subcluster in reedfish. Syntenic and phylogenetic analyses revealed that two pairs of $k r t 18 / k r t 8$ keratin genes were shared among all vertebrates, thus implying that they encode ancestral type I and II keratin protein sets. We further revealed that distinct keratin gene subclusters, which show specific expressions in the epidermis of adult amphibians, stemmed from canonical keratin genes in non-terrestrial ancestors. Molecular evolutionary analyses suggested that the selective constraints were relaxed in the adult epidermal subclusters of amphibians as well as the novel subcluster of reedfish. The results of the present study represent the process of diversification of keratins through a series of gene duplications that could have facilitated the terrestrial adaptation of vertebrates. 


\section{Introduction}

Vertebrate skin structure dramatically changed during the evolutionary transition of vertebrates from aquatic living as fish to terrestrial living as mammals. In the process of terrestrial adaptation, amniotes (e.g., mammals, birds, and reptiles) acquired the stratum corneum, an outer epidermal layer that is filled with keratinous fibers, to guard the skin against drying (Schempp et al., 2009; Yokoyama et al., 2018). By contrast, the skin of bony fish is covered with bony scales to protect them from predators. Amphibians, a basal lineage of terrestrial vertebrates, do not possess scales. According to Szarski (1962), the lack of scales allows amphibians to reduce their body weight as well as to breathe through their skin. Alibardi (2001) described the existence of an amniote-like stratum corneum in the epidermis of adult frogs, but not in tadpoles or aquatic lungfish, implying that the acquisition of the stratum corneum is key to terrestrial adaptation.

Keratin proteins are intermediate filaments and main components of the stratum corneum. Keratin proteins combine with filaggrin to provide durability and prevent water loss from epidermal cells (Sandilands et al., 2009). Keratin proteins are divided into two classes (type I and type II), which are strictly interdependent for assembly into filaments and form coiled-coil heterodimers during the first stage of the process (Jacob et al., 2018). In tetrapods, keratin genes form two clusters (clusters 1 and 2), each of which is mostly dominated by type I and II keratin genes, respectively (Hesse et al., 2004; Zimek and Weber, 2006). However, such gene clusters were not observed in teleost fishes (Zimek and Weber, 2005; Vandebergh and Bossuyt, 2012). Phylogenetic analyses revealed the reciprocal monophyly of type I and type II keratin genes (Schaffeld and Schultess, 2006; Suzuki et al., 2017). The expansion of the keratin genes is believed to have contributed to the terrestrial adaptation (Vandebergh and Bossuyt, 2012). For example, terrestrial vertebrates possess a higher number of keratin genes compared to teleosts despite the whole genome duplication that teleosts underwent. However, this may be the result of massive gene loss that followed this event (Zimek and Weber, 2005). Aquatic mammals lost several keratin genes for outer epidermal layers that would be essential in order 
to effectively survive in terrestrial environments (Ehrlich et al., 2019). Some keratin genes show specific expressions in particular developmental stages and tissues in adult epidermis (Watanabe et al., 2001, 2002). A recent genome-wide analysis on keratin genes in Xenopus laevis and X. tropicalis revealed that they possess 4-10 genes for both type I and II keratins, which are specifically expressed in the adult epidermis. These keratin genes form two "adult epidermal keratin subclusters" that are located in each of the two keratin gene clusters (Suzuki et al., 2017).

Although the expansion of the keratin genes in the clusters may be involved in the terrestrial adaptation of vertebrates, the origin and process of keratin gene diversification still remain unclear. Until now, type I and II keratin genes were characterized not only in terrestrial vertebrates but also in early diverged vertebrates such as lamprey and shark (Vandebergh and Bossuyt, 2012); bichir, sturgeon, and gar (Schaffeld et al., 2007); teleosts (Zimek and Weber, 2005); and lungfish (Schaffeld et al., 2005). The origin of the keratin gene clusters was expected to date back to Chondrichthyes (Vandebergh and Bossuyt, 2012). However, the existence of the cluster has not yet been explored in the genomes of Chondrichthyes, Sarcopterygii, and basal Actinopterygii. Thus, characterization and comparison of the clusters in the species of these classes at the whole genome level are of chief importance in order to fill the evolutionary gap between fish and terrestrial vertebrates. In the present study, we revealed the existence of two major keratin clusters, which are conserved among Chondrichthyes, basal Actinopterygii, coelacanths, and terrestrial vertebrates. We also discovered that a set of $k r t 18 / k r t 8$ genes is highly conserved in all vertebrates in a head-to-head array, implying that they could be ancestral keratin pairs. In addition to these two major clusters, we found a novel subcluster of keratin genes that were specifically expanded in reedfish. Phylogenetic and syntenic analyses revealed that the keratin genes belonging to the "adult epidermal keratin subclusters" stem from canonical keratin genes that have already existed in the keratin clusters of non-terrestrial ancestors. Selection analysis suggests relaxation of purifying selection in the reedfish-specific subcluster and the "adult epidermal keratin subclusters" of amphibians. On the basis of our results, we discuss the evolutionary process and the possible contribution of keratin gene expansion that lead to 
bioRxiv preprint doi: https://doi.org/10.1101/2020.05.06.063123; this version posted October 5, 2020. The copyright holder for this preprint (which was not certified by peer review) is the author/funder, who has granted bioRxiv a license to display the preprint in perpetuity. It is made available under aCC-BY-NC 4.0 International license.

epidermal diversification and terrestrial adaptation in vertebrates. 


\section{Methods}

\subsection{Keratin gene sequences and locations}

We collected data for the sequences, locations, and orientation of keratin genes in Callorhinchus milii (elephant shark; Assembly Callorhinchus_milii-6.1.3; NCBI Annotation Release 100; Venkatesh et al., 2014), Erpetoichthys calabaricus (reedfish; Assembly fErpCal1.1; NCBI Annotation Release 100), Lepisosteus oculatus (spotted gar; Assembly LepOcu1; NCBI Annotation Release 101; Braasch et al., 2016), Latimeria chalumnae (coelacanth; Assembly LatCha1; NCBI Annotation Release 101; Amemiya et al., 2013), Rhinatrema bivittatum (caecilian; Assembly aRhiBiv1.1; NCBI Annotation Release 100), Xenopus tropicalis (western clawed frog; Assembly UCB_Xtro_10.0; NCBI Annotation Release 104; Hellsten et al., 2010) and Petromyzon marinus (lamprey; Assembly kPetMar1.pri; NCBI Annotation Release 100) that were deposited in the National Center for Biotechnology Information (NCBI) Database (https://www.ncbi.nlm.nih.gov/). Data for Branchiostoma belcheri (amphioxus) were collected from Branchiostoma.belcheri_HapV2(v7h2) through LanceletDB (http://genome.bucm.edu.cn/lancelet/; You et al., 2019). All of the collected sequences were manually inspected to determine whether the gene was pseudogenized or not. The amino acid and nucleotide sequences, and the location of the intact and pseudogenes were summarized in Supplementary Files S1-3. The keratin gene sequences of Protopterus dolloi (lungfish) were obtained from RNA-seq data for skin tissue (SRX4966457) and pectoral fins (SRX895362; Takezaki and Nishihara, 2016). Raw read data were assembled de novo with Trinity (Grabherr et al., 2011) using the default settings and were extracted keratin gene sequences from assembled data with FATE (Suzuki, 2017) with BLASTN (Altschul et al., 1990) and exonerate (Slater and Birney, 2005) using the coelacanth keratin gene as a query. If the sequences were more than $99 \%$ similar, only one sequence was extracted. Gene names were assigned according to NCBI nomenclature and previous studies. 


\subsection{Phylogenetic analysis for all keratin genes}

We constructed a phylogenetic tree of keratin genes for a broad range of vertebrates and amphioxi. Amino acid sequences for keratins of amphioxi, lampreys, elephant sharks, reedfish, spotted gars, coelacanths, lungfish, caecilians, and western clawed frogs were used for analysis. These sequences were aligned using MAFFT version 7 (Katoh and Toh, 2008) with the E-INS-i parameter, and over $50 \%$ of gap sites were removed. The phylogenetic tree was generated using RAxML version 8.2.12 (Stamatakis, 2014) with the amino acid substitution LG + F model and 300 bootstrap replicates. The model was determined using MEGA X (Kumar et al., 2018).

\subsection{Quantitative analysis: expression of epidermal keratin in adult amphibians}

To identify keratin genes that are expressed in the epidermis of adult amphibians, we analyzed RNA-seq data of Rhinatrema bivittatum skin (SRR5591419; Torres-Sánchez et al., 2019) and Xenopus tropicalis skin (SRR1405691 and SRR1405692). The read data were checked for quality, and quality control was performed with PRINSEQ++ (Cantu et al., 2019) using the following settings: “-trim_left 5 -trim_tail_right 5 -trim_qual_right 30 -ns_max_n 20 -min_len 30.” After quality control, the read data were mapped to reference genomes (aRhiBiv1.1 and UCB_Xtro_10.0) with STAR version 2.7 (Dobin et al., 2013), and the read counts were normalized with TPMCalculator (Vera Alvarez et al., 2019). The resulting data were summarized in Supplementary Table S2. TPM values ( $>100)$ were used as criteria to determine whether keratin genes were expressed in the adult epidermis.

\subsection{Selection analysis}

To evaluate the relaxation of purifying selection on sequences of keratin genes, we calculated the non-synonymous substitution rate to synonymous substitution rate ratio $\left(d_{\mathrm{N}} / d_{\mathrm{S}}\right)$ for several clades of interest. The nucleotide sequences of keratin genes were analyzed by separating them into type I and type II. The translated amino acid sequences were aligned in MAFFT using default parameters (Katoh et al., 2002). This multiple alignment of amino acid sequences was converted into a codon 
alignment using PAL2NAL (Suyama et al. 2006). We used the CodeML program in PAML 4.9j (Yang, 2007) to analyze branch models (Yang, 1998) for branches where the keratin genes revealed an expansion in copy numbers. We used the CF2 model, where codon frequencies are calculated from the average nucleotide frequencies at the three codon positions, for analysis. To assess the statistical significance of the elevation of the $d_{\mathrm{N}} / d_{\mathrm{S}}$ ratio for each branch, likelihood ratio tests and inspections of the p-value were used to compare likelihoods between two models by assuming that the $d_{\mathrm{N}} / d_{\mathrm{S}}$ ratio was not changed in all branches (null hypothesis) and that the $d_{\mathrm{N}} / d_{\mathrm{S}}$ ratio was only changed in foreground branches (alternative hypothesis). 


\section{Results}

\subsection{Keratin gene clusters conserved among ancient fishes}

An exploration of keratin genes from the genomes from one Cephalochordata (amphioxus), one Cyclostomata (sea lamprey), one Chondrichthyes (elephant shark), two basal Actinopterygii (spotted gar and reedfish), one Actinistia (coelacanth), and two Amphibia (caecilian and western clawed frog) gave an overview of the genomic organization of vertebrate keratin gene clusters (Fig. 1; Supplementary Table S1). In terrestrial vertebrates, type I keratin genes in cluster 1 are flanked by smarcel and eif1, and type II keratin genes (and only one type I keratin gene) in cluster 2 are flanked by faim 2 and eif $4 b$. In teleosts, however, syntenic relationships were not observed in either type I or type II keratin genes (Zimek and Weber, 2005; Vandebergh and Bossuyt, 2012). Here, we revealed that the syntenic relationship of type I keratin genes in cluster 1 was highly conserved among elephant shark, spotted gar, reedfish, coelacanth, and terrestrial tetrapod genomes (Fig. 1). The type I keratin genes of reedfish and spotted gar that are flanked by smarcel and eifl in cluster 1 were monophyletic in the phylogenetic tree (Fig. 2; D). We named these keratin genes "krt49." One of the krt49 genes krt49.1 - exists outside the cluster that is bounded by smarcel.

We also found syntenic relationships in type II keratin genes in cluster 2, although they were somewhat weak compared to those in cluster 1. For example, coelacanths possess the type II keratin gene cluster, which is flanked by eif $4 b$ and faim2, as shown in terrestrial tetrapods. In spotted gars and reedfish, eif4b exists at the end of the cluster, but faim 2 is absent in the opposite end of the cluster. Elephant sharks possess cluster 2, which is represented by several type II genes but only one type I keratin gene (krt18s). However, it was not flanked by eif $4 b$ and faim2 (Fig. 1).

In addition to the major clusters 1 and 2 localized in two genomic regions (Vandebergh and Bossuyt, 2012), we found a novel keratin gene subcluster 3, where 13 genes were tandemly duplicated, in reedfish (Fig. $1 \mathrm{C}$ ). The keratin genes arranged in this subcluster are homologs of krt48s. Initially, $k r t 48$ s were identified by Schaffeld et al. (2007) as "krt14". We re-named these genes as " $k r t 48$ " to 
avoid confusion in referring krt14 in mammals. krt48s are shared by elephant sharks, gars, sturgeon, and coelacanths, but were not extensively expanded in these species. None of the krt48 genes shared any synteny with cluster 1 or 2 , implying that this subcluster is distinct from the two major clusters. Interestingly, one copy of krt48 was found in the basal lineage of the amphibian Rhinatrema bivittatum but not in the other terrestrial vertebrates (Figs. 1 and 2). We also found subcluster 4, in which only one set of $k r t 18 \mathrm{~s}$ and $k r t 8 \mathrm{~s}$ existed (Fig. 1). This subcluster is also distinct from the two major clusters 1 and 2 as no synteny relationships were observed. Subcluster 4 exists in a broad range of vertebrates, but it was not found in some terrestrial vertebrates such as caecilians, birds, and mammals. 


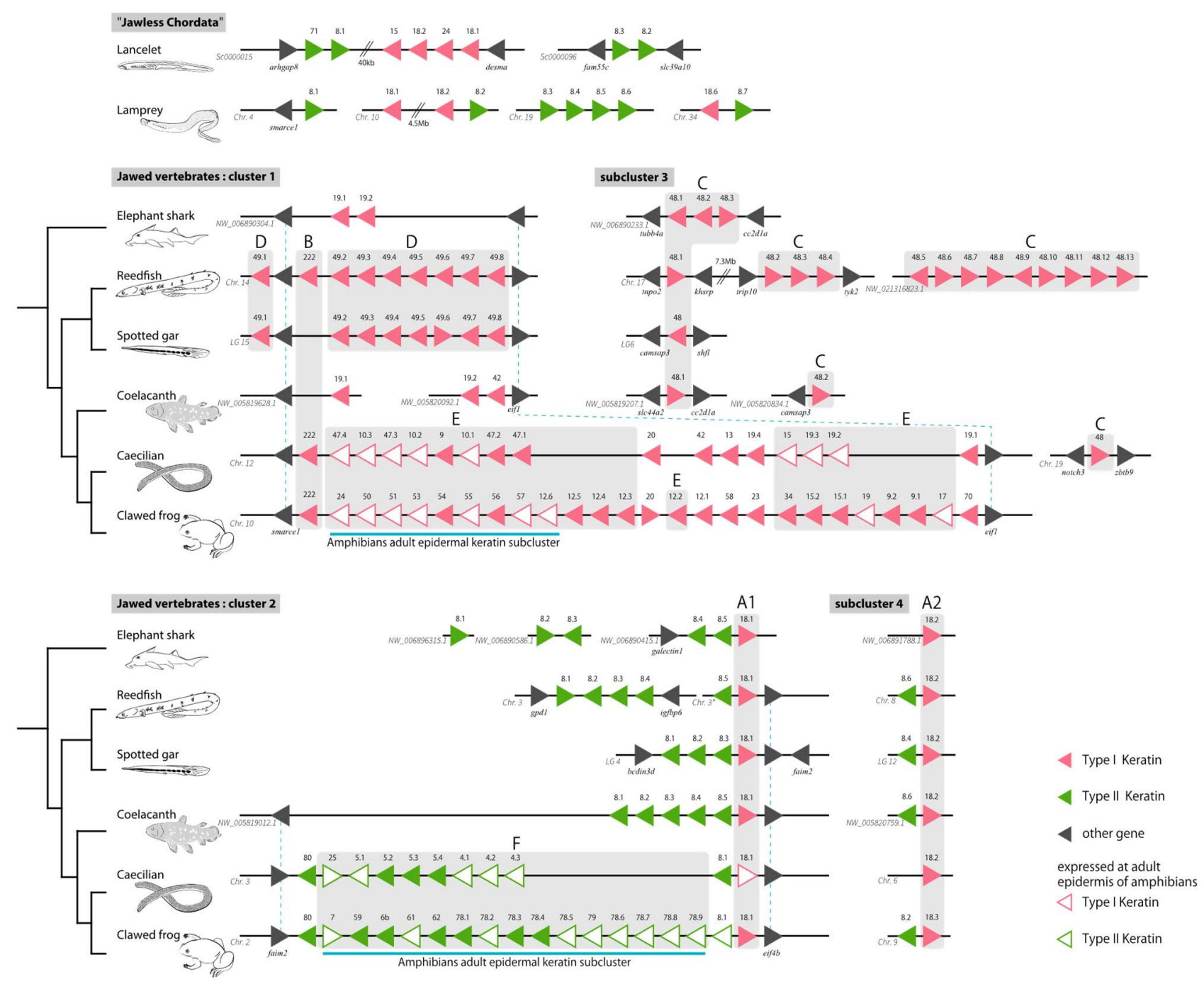

Fig. 1. Comparison of keratin gene clusters in vertebrates and amphioxus. The keratin gene clusters were compared among amphioxus (Branchiostoma belcheri), lamprey (Petromyzon marinus), elephant shark (Callorhinchus milii), reedfish (Erpetoichthys calabaricus), spotted gar (Lepisosteus oculatus), coelacanth (Latimeria chalumnae), caecilian (Rhinatrema bivittatum), and western clawed frog (Xenopus tropicalis). Lines indicate a continuous genomic scaffold, linkage group, or chromosome. Double slashes indicate an abbreviated genomic region. Type I keratin genes, type II keratin genes, and non-keratin genes are indicated by pink, green, and black triangles, respectively. The keratins that are expressed in the epidermis of adult amphibians are indicated with white triangles. All triangles indicate the transcriptional direction of genes for each chromosome or scaffold (LG). Gray boxes with letters correspond to the clades in the phylogenetic tree (Fig. 2). The chromosome, linkage group, and scaffold are shown in the lower left of black lines. Asterisk: unlocalized scaffolds of chromosome 3 . 


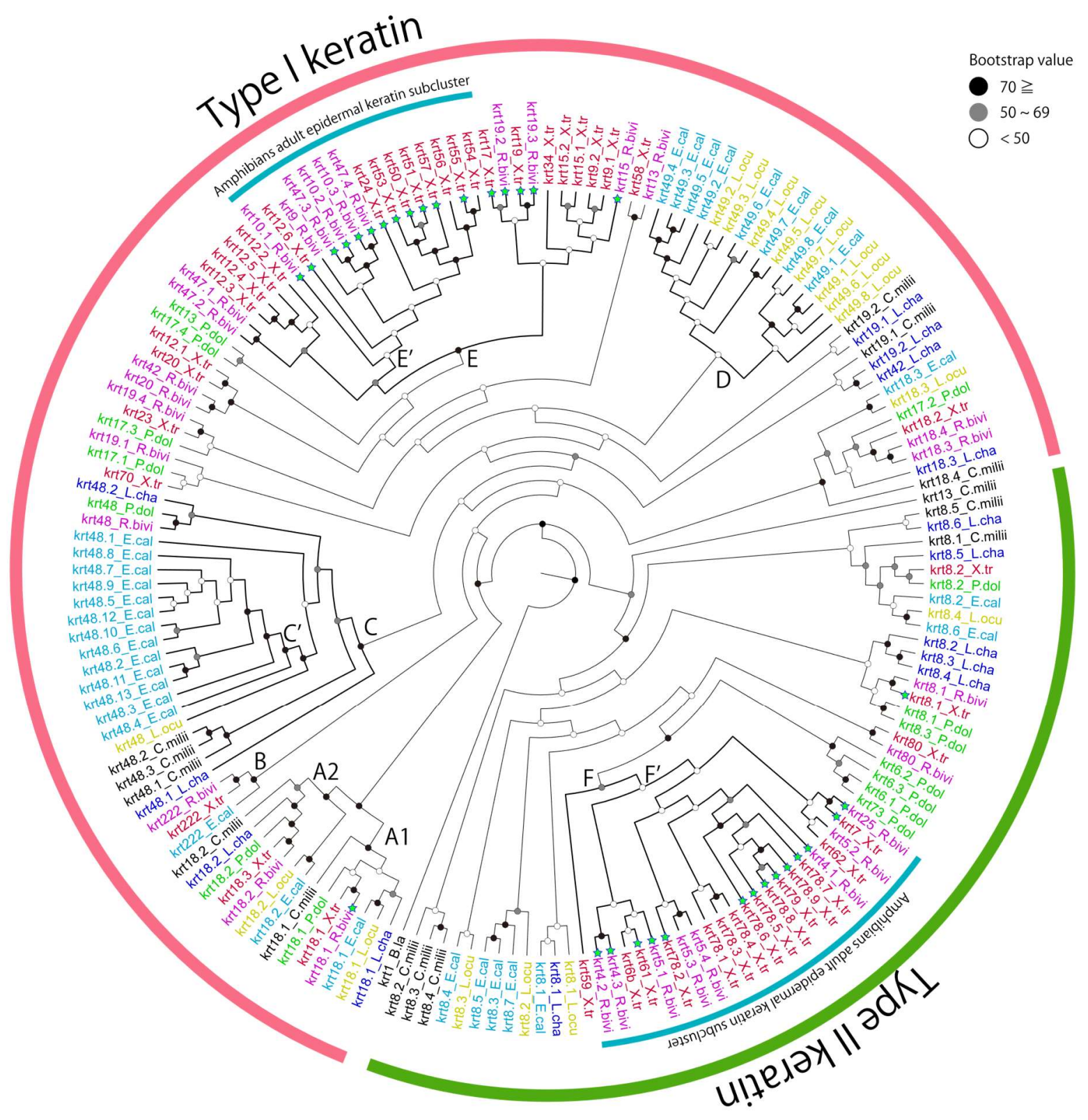

Fig. 2. Phylogenetic tree of type I and II keratin genes. The species included in the tree are the following: elephant shark (C. milii; C.milli, black), reedfish (E. calabaricus; E.cal, light blue), spotted gar (L. oculatus; L.ocu, yellow), coelacanth (L. chalumnae; L.cha, blue), lungfish (P. dolloi; P.dol, green), caecilian (R. bivittatum; R.bivi, purple), and western clawed frog (X. tropicalis; X.tr, red). The sequence of keratin k1 of Branchiostoma lanceolatum was designated as the outgroup (CAB75942.1). Black, gray, and white circles on the nodes indicate bootstrap values 70 and over, 50 to 69, and under 50 , respectively. Green stars indicate the expression of keratin genes in the skin of adult $R$. bivittatum and $X$. tropicalis. Letters near the nodes correspond to the gray boxes in Fig. 1. 


\subsection{Highly conserved keratin gene set $k r t 18 / k r t 8$}

We revealed that several keratin genes are highly conserved among a broad range of vertebrates as represented by krt18s (clades A1 and A2) and krt8s (Fig. 1), which were shown to be shared in terrestrial vertebrates (Balmer et al., 2017; Vandebergh and Bossuyt, 2012; Ehrlich et al., 2019). It is important to note that the head-to-head array of $k r t 18 \mathrm{~s}$ and $k r t 8 \mathrm{~s}$ in cluster 2 and that in subcluster 4 , in which the $5^{\prime}$ ends of two adjacent genes face each other, were highly conserved from sharks to terrestrial vertebrates (Fig. 1). The characteristic head-to-head arrays of krt $18 \mathrm{~s}$ and $k r t 8 \mathrm{~s}$ are observed exclusively in these two loci. Although the synteny relationships are not obviously identified, we found two pairs of head-to-head $k r t 18 / k r t 8$ in the lamprey genome, the most basal lineage of vertebrates (Fig. 1). We also found the keratin gene sequences, which were assigned as "krt18s," in the amphioxus genome. However, these genes are not arranged in a head-to-head manner with type II keratins (Fig. 1). Phylogenetic analysis suggests that krt18.1 (clade A1) and krt18.2 (clade A2) from shark to terrestrial vertebrates are monophyletic and these two clades are most ancestral in type I keratin genes (Fig. 2). The additional phylogenetic analyses that focus on the krt18s and $k r t 8 s$ of lampreys and amphioxi revealed that the krt18.1 and krt18.2 of lampreys are sister groups of clades A1 and A2 (Fig. S1). By contrast, krt18s of amphioxi diverged quite earlier than those of vertebrates (Fig. S1). krt222 (clade B) is also found in a broad range of vertebrates from reedfish to western clawed frogs as well as mammals (Ehrlich et al., 2019). However, they became pseudogenes in elephant sharks, spotted gars, and coelacanths (Fig. 1; B).

\subsection{Copy number of keratin genes among vertebrates}

We counted and compared the total number of intact keratin genes among vertebrates (Fig. 3). By taking the phylogenetic tree into account, the type I keratin genes had increased after the emergence of tetrapods. The number of type I keratin genes was constant in most fish of Actinopterygii lineages, except for reedfish where 25 genes were observed. The increase of type I keratin genes in reedfish is explained by the expansion of krt48 in subcluster 3 (Fig. 1). The number of type II keratin genes was 
also constant in fish lineages but suddenly increased in the common ancestor of terrestrial vertebrates. In spite of the fact that the ancestor of teleosts experienced whole genome duplication, the copy number of keratin genes is not higher than that of other fish species. The marked increase of keratin genes was observed in tetrapods and reedfish.

In addition, we counted the number of cysteine residues in keratins (Fig. S2). The number of cysteines were significantly higher in a mammal and amphibians than in fish, which possess only a few cysteines. Although it is not statistically significant, the number of cysteines were high in lamprey and lungfish. 


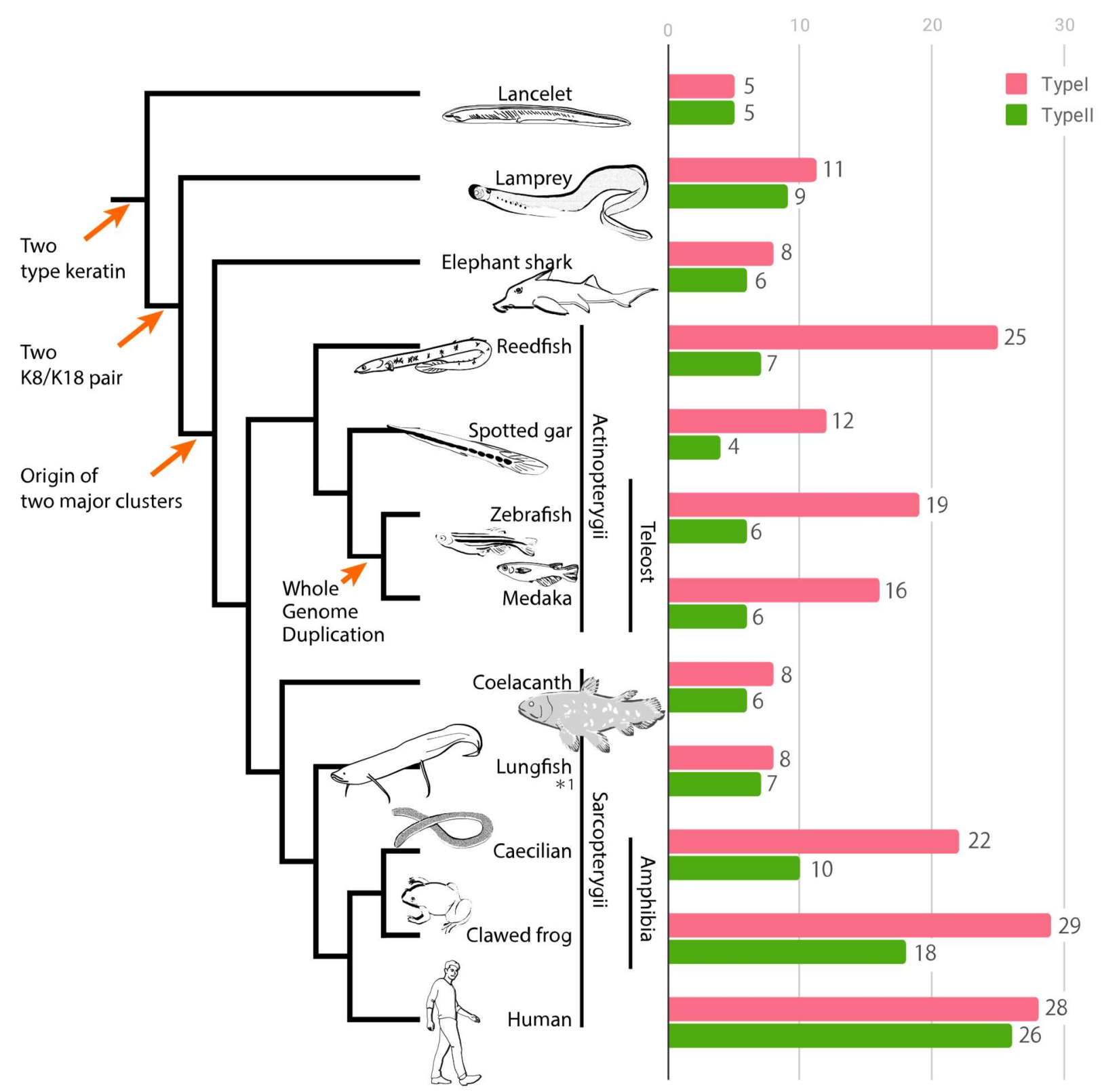

Fig. 3. The number of keratin genes among vertebrates and amphioxus. The number of intact keratin genes was compared among Cephalochordata (amphioxus), Cyclostomata (lamprey), Chondrichthyes (Elephant shark), Actinopterygii, and Sarcopterygii (including Amphibia). Type I keratin: pink bar; type II keratin: green bar. Arrows in the phylogenetic tree indicate the timing of the evolutionary events. *1: The number of keratin genes of lungfish estimated using data obtained from RNA-seq analysis. 


\subsection{Origin of "adult epidermal keratin subcluster" in amphibians}

In clawed frogs, some keratin genes in both types I and II are specifically expressed in the epidermis of the adult stage but not in the tadpole epidermis (Suzuki et al., 2017; Fig. 2, white triangle). These keratin genes possibly contribute to the adaptation to the terrestrial environment. To explore the evolutionary origin of the adult epidermal keratin subcluster, we performed phylogenetic analyses of keratin genes by adding the keratin genes of ancient fishes and another amphibian species, Rhinatrema bivittatum, which is the most basal lineage of extant amphibia (caecilians or Gymnophiona). We also analyzed public RNA-seq data for adult caecilian and western clawed frog to identify which keratin genes were expressed in their skin (Supplementary Table S2). The results of our phylogenetic analysis show that keratin genes, which are expressed in epidermis of caecilians, are included in the clades of the "adult epidermal keratin subcluster" of western clawed frogs (Fig. 2; E, F). Additionally, the locations of these adult epidermal keratin genes in the caecilian genome are close to those in the western clawed frog (Fig. 1; E, F). For lungfish, we also identified the keratin genes that are expressed in skin and pectoral fin using public RNA-seq data. Subsequent phylogenetic analyses suggested that keratin genes expressed in the skin and pectoral fins of lungfish were not included in the amphibian adult epidermal keratin subclusters. It is noteworthy that the phylogenetic and syntenic analyses revealed that the adult epidermal keratins, which belong to clades $\mathrm{E}$ and $\mathrm{F}$, shared common ancestry with $k r t 49$ s (clade D, type I) and krt8s (type II) that had already existed in the common ancestor of bony fish.

\subsection{Relaxation of purifying selection in keratin genes}

The $d_{\mathrm{N}} / d_{\mathrm{S}}$ ratio provides useful insight into the strength and mode of natural selection acting on protein-coding genes. In particular, the elevation of the $d_{\mathrm{N}} / d_{\mathrm{S}}$ ratio can be used to evaluate the operation of natural selection toward functional diversification. To examine the extent of diversification in several keratin gene clusters, we calculated $d_{\mathrm{N}} / d_{\mathrm{S}}$ values by defining the branches of the clusters of interest as foreground and the other branches as background. We performed the analyses 
on clades $\mathrm{C}-\mathrm{F}$ and $\mathrm{C}^{\prime}, \mathrm{E}^{\prime}$, and $\mathrm{F}^{\prime}$ in the phylogenetic tree shown in Fig. 2. The copy number of reedfish krt48 was increased by gene duplication compared to other species ( $\mathrm{C}$ and $\mathrm{C}^{\prime}$ in Fig. 2). Clades $\mathrm{E}$ and F contain "adult epidermal keratin" subcluster genes of amphibians (Fig. 2). E' and F' were monophyletic groups of amphibian adult epidermal keratin subcluster genes. The summary of this analysis is shown in Table 1 . The $d_{\mathrm{N}} / d_{\mathrm{S}}$ values among all branches were within the range of 0.1 to 0.3 , suggesting that most keratin genes may be under purifying selection. Importantly, however, the $d_{\mathrm{N}} / d_{\mathrm{S}}$ values of $\mathrm{C}^{\prime}$ (reedfish-specific type I $k r t 48$ branch), $\mathrm{E}^{\prime}$, and $\mathrm{F}^{\prime}$ (type I and type II amphibian "adult epidermal keratin" subcluster branches) were higher $\left(C^{\prime}: 0.29, E^{\prime}: 0.25\right.$, and $\left.F^{\prime}: 0.15\right)$ than background $(0.18,0.18$, and 0.13 , respectively) with statistical significance. The results suggest that the constraints of purifying selection were relaxed in these branches, implying the operation of natural selection toward functional diversification in these clusters. 
Table 1. Summary of the results of selection analyses and likelihood ratio tests.

\begin{tabular}{|c|c|c|c|c|}
\hline clade C & $n p^{1}$ & $\operatorname{lnL}$ & p-value ${ }^{2}$ & $d_{\mathrm{N}} / d_{\mathrm{S}}$ \\
\hline Null hypothesis & 224 & -65270.5166 & \multirow{2}{*}{0.0679} & 0.1797 \\
\hline Alternative hypothesis & 225 & -65268.8495 & & 0.2066 \\
\hline clade $\mathrm{C}^{\prime}$ & $\mathrm{np}$ & $\operatorname{lnL}$ & $\mathrm{p}$-value & $d_{\mathrm{N}} / d_{\mathrm{S}}$ \\
\hline Null hypothesis & 224 & -65270.5166 & \multirow{2}{*}{0.0002} & 0.1791 \\
\hline Alternative hypothesis & 225 & -65263.7851 & & 0.2919 \\
\hline clade D & $\mathrm{np}$ & $\operatorname{lnL}$ & p-value & $d_{\mathrm{N}} / d_{\mathrm{S}}$ \\
\hline Null hypothesis & 224 & -65270.5166 & \multirow{2}{*}{0.1937} & 0.1796 \\
\hline Alternative hypothesis & 225 & -65269.6720 & & 0.1951 \\
\hline clade E & $\mathrm{np}$ & $\operatorname{lnL}$ & p-value & $d_{\mathrm{N}} / d_{\mathrm{S}}$ \\
\hline Null hypothesis & 224 & -65270.5166 & \multirow{2}{*}{0.1145} & 0.1772 \\
\hline Alternative hypothesis & 225 & -65269.2711 & & 0.1916 \\
\hline clade $E^{\prime}$ & $\mathrm{np}$ & $\ln \mathrm{L}$ & p-value & $d_{\mathrm{N}} / d_{\mathrm{S}}$ \\
\hline Null hypothesis & 224 & -65270.5166 & \multirow{2}{*}{ 4.E-10 } & 0.1702 \\
\hline Alternative hypothesis & 225 & -65250.8822 & & 0.2525 \\
\hline clade F & $\mathrm{np}$ & $\ln \mathrm{L}$ & p-value & $d_{\mathrm{N}} / d_{\mathrm{S}}$ \\
\hline Null hypothesis & 116 & -26448.0867 & \multirow{2}{*}{0.0501} & 0.1265 \\
\hline Alternative hypothesis & 117 & -26446.1671 & & 0.1474 \\
\hline clade $\mathrm{F}^{\prime}$ & $\mathrm{np}$ & $\operatorname{lnL}$ & $\mathrm{p}$-value & $d_{\mathrm{N}} / d_{\mathrm{S}}$ \\
\hline Null hypothesis & 116 & -26448.0867 & \multirow{2}{*}{0.0137} & 0.1250 \\
\hline Alternative hypothesis & 117 & -26445.0481 & & 0.1518 \\
\hline
\end{tabular}

${ }^{1}$ np: number of free parameters. ${ }^{2}$ p-value: statistical significance for the likelihood ratio test between null hypothesis and alternative hypothesis. 


\section{Discussion}

\subsection{Conservation of two major keratin gene clusters in early vertebrates}

Two keratin gene clusters exist in terrestrial vertebrates, but not in teleost fishes (Zimek and Weber, 2005; Vandebergh and Bossuyt, 2012). Since the existence of keratin gene clusters has not been explored in an ancestral group of vertebrates, the timing for the first appearance of these clusters was unclear. Indeed, type I and II keratin genes were identified in ancient lineages of vertebrates such as lamprey, shark, bichir, sturgeon, and gar (Schaffeld et al., 2007; Vandebergh and Bossuyt, 2012). However, the synteny relationships of these genes could not be uncovered because the genome sequences were not available. In the present study, by exploring the whole genome sequences of the aforementioned species, we revealed the existence of both keratin gene clusters 1 and 2, each of which is flanked by two marker genes (Fig. 1). Although the marker genes were not found in cluster 2 of elephant shark and lamprey, the tandem array of the keratin genes indicates the existence of the cluster in these species. Thus, our present study suggests that the origin of the two keratin gene clusters dates back to the common ancestor of Vertebrata.

Although some ancient fish with keratin cluster (such as reedfish and spotted gar) have ganoid scale, the epidermal skin structures are basically similar with the other teleost fishes (Sire, 1995). Thus, it is unlikely that the presence of keratin cluster itself directly contributed to the acquisition of skin structures adapted to terrestrial environments. The evolutionary significance for the existence of keratin cluster in ancient fish could be explained by “exaptation”. Keratin genes of terrestrial tetrapods are packaged together at particular genomic locations and expression stages (Ehrlich et al., 2019; Suzuki et al., 2017), which may be important to accomplish the terrestrial adaptation. Indeed, recent study revealed that a single enhancer regulates the expression of many beta-keratin genes in the cluster (Liang et al., 2020). From that perspective, the presence of keratin clusters in fish prior to terrestrial adaptation may be an "exaptation". In other words, the clustered keratin genes arrangement in ancient fish were subsequently "co-opted" in terrestrial tetrapods. 


\subsection{Ancient and conservative keratin gene pair $k r t 18 / k r t 8$}

One of the interesting findings in keratin gene cluster 2 is that $k r t 18.1$ and $k r t 8$ s were located in a head-to-head array that is highly conserved from lamprey to tetrapods (Fig. 1; A1). krt18.1 is exceptional in that it is arranged with type II keratin genes in cluster 2 even though they belong to type I in the phylogenetic tree (Fig. 2). We newly found that krt18.2 and krt8s were located in a head-tohead array in subcluster 4 that is also conserved among a broad range of vertebrates (Fig. 1; A2). It is worth noting that Schaffeld et al. (2005) presumed that krt18/krt8 found in terrestrial vertebrates has true orthologs in all Gnathostomata (i.e., jawed vertebrates) and possibly in Cyclostomata (i.e., lamprey and hagfish). Our data support this hypothesis by showing the characteristic synteny relationships of these genes. Phylogenetic analysis suggests that the $k r t 18 \mathrm{~s}$ belonging to A1 and A2, which have head-to-head orientation with $k r t 8$ s, are monophyletic at the basal position in type I keratin genes (Fig. 2). We expect that the two pairs of $k r t 18 \mathrm{~s} / k r t 8$ s found in lamprey are the ancestral genes leading to cluster 2 and subcluster 4 in all extant vertebrates. It is implicative that the set of $k r t 18 / k r t 8$ is shown to be first expressed during mammalian embryogenesis (Duprey et al., 1985). These lines of data and observations imply that highly diversified keratin genes in vertebrates originated from the set of $k r t 18 / k r t 8$, which possess essential and fundamental developmental functions.

\subsection{Additional $k r t 48$ subcluster in reedfish}

In addition to the two major clusters conserved among Gnathostomata (this study; Vandebergh and Bossuyt, 2012), we newly discovered subcluster $\mathrm{C}$ in reedfish (Fig. 1). Given that the krt48s in subcluster $\mathrm{C}$ are monophyletic in the phylogenetic tree (Fig. 2), all of these genes originated from a single ancestral gene through duplications. Initially, krt48s were identified by Schaffeld et al. (2007), in which 1 or 2 copies of $k r t 48$ s were only found in basal Actinopterygii (e.g., bichir, sturgeon, and gar). In this study, we revealed that $k r t 48 \mathrm{~s}$ are shared among various vertebrates from shark to amphibians (e.g., caecilian), but not in reptiles, chickens, or mammals. The distribution of krt48s in 
vertebrate genomes suggests that they were acquired in the common ancestor of Gnathostomata and were lost after the divergence of amphibians. Our phylogenetic analysis suggested that $k r t 48$ s diverged next to krt18s (Fig. 2). This branching order is not consistent with a previous study (Schaffeld et al., 2007), in which $k r t 48$ s are the basal in type I keratin genes. We suppose that the increase in the number of sequences of $k r t 48 \mathrm{~s}$ and $k r t 18 \mathrm{~s}$ outgroups for the analysis is due to the availability of the whole genome sequences, which may facilitate a more accurate tree estimation.

\subsection{Genome duplication and copy number variation}

It is well established that teleost fish have undergone teleost-specific genome duplication (3R; Meyer and Van de Peer, 2005). Zimek and Weber (2005) presumed that 3R caused the dispersal of the keratin gene cluster, which led to the breakdown of the syntenic relationships of the clusters between teleosts and terrestrial vertebrates. In the present study, we revealed that both of the keratin gene clusters were conserved in basal Actinopterygii, which have not undergone 3R (Fig. 1), supporting the hypothesis by Zimek and Weber (2005) that the 3R resulted in the breakdown of the clusters in teleosts.

We found that the copy number of keratin genes was constant in both types of keratin genes among fish from shark to coelacanth, except for reedfish. In particular, the copy number was also constant in teleosts despite the $3 \mathrm{R}$ that they experienced that led to the disruption of gene clusters (Fig. 3). The conservative copy number among fish implies that these keratins were under strict purifying selection for survival in underwater environments. By contrast, the number of keratin genes was expanded in terrestrial vertebrates and reedfish, which raises the possibility of adaptive evolution in these groups (see latter discussion).

It is noteworthy that the number of type I and II keratins are almost symmetric in mammals, shark and lamprey (Vandebergh and Bossuyt, 2012; Ehrlich et al., 2019; this study), whereas asymmetric in Actinopterygii and amphibians (Fig. 3). One possible explanation for the symmetry in mammals may be "one to one co-expression" of type I and II keratin pairs. However, only a limited number of examples for one to one co-expression were shown in mammals (ex. Chu and Weiss, 2002) 
as well as in fish. Therefore, at present, it is difficult to provide clear answer for the symmetry/asymmetry of the number of type I and II keratins. We can only to discuss that difference in the number of type I and II keratins in Actinopterygii is due to the acceleration of species-specific duplication of type I genes in this group.

\subsection{Origin of keratin genes specific to terrestrial vertebrates}

Terrestrial vertebrates possess a higher number of keratin genes compared to fish, which may have facilitated their invasion of terrestrial environments. The keratin genes that belong to the "adult epidermal keratin subcluster" in clawed frogs (Suzuki et al., 2017) were also shown to be expressed in the skin of adult caecilians (Fig. 1, Fig. 2; E, F). In the present study, no keratin genes that belong to the "adult epidermal keratin subcluster" was found in the RNA-seq data of the skin and fins of lungfish, implying that they do not possess keratin genes belonging to this subcluster. However, it is possible that the "adult epidermal keratin genes" were not expressed in lungfish skin in underwater environments. Indeed, Heimroth et al. (2018) reported that the epidermis of lungfish showed notable changes and became more compact with flattened keratinocytes in response to experimental terrestrial conditions. Therefore, it would be worthwhile to analyze the RNA-seq data collected from the skin of this terrestrial condition to examine the above possibility. Furthermore, analysis of the whole genome, which is not available at present, may lead to the identification of such keratin genes in lungfish.

Phylogenetic and syntenic analyses supported that the "adult epidermal keratin subcluster" of terrestrial vertebrates stemmed from the keratin genes in clusters 1 and 2 that had already existed in the common ancestor of Actinopterygii and Sarcopterygii (Figs. 1,2). The terrestrial adaptation could be partly facilitated by the diversification of keratin genes through the co-option of existing keratin genes.

\subsection{Cysteine residues of keratin genes}

Recently, crystal structures of human krt10/krt1 and krt14/krt5 had been determined (Bunick 
and Milstone, 2017). In krt10/krt1 pair, Cys401 ${ }^{\mathrm{K} 10}$, which is conserved among mammals, was shown to be essential to form heterodimer via disulfide link. The mutation at this residue results in a significantly increased trans-epidermal water loss in mice skin (Guo et al., 2020). The cysteine residue at the corresponding site is also conserved in krt14 among mammals (Lee et al., 2012). To examine the presence/absence of this conserved cysteine residue among broad range of vertebrates, we aligned type I keratin amino acid sequences including human krt10 and krt14. Alignment of keratin sequences revealed that this cysteine residue only exists in keratins expressed in the adult epidermis of amphibians in addition to mammals (Fig. S3). We found that fish do not possess keratins which possess the cysteine residue at the corresponding site of $\mathrm{Cys} 401^{\mathrm{K} 10}$. Therefore, our comparative sequence analyses suggest that this cysteine residue may play an important role in terrestrial adaptation.

Our result showed that the number of cysteines in keratins were significantly higher in terrestrial tetrapods (mammals and amphibians) than in fish, which contain only a few cysteines (Fig. S2). Above data imply that the increase of cysteines in keratins may allow ancestral amphibians to acquire hardness in their scaleless epidermis during evolution (Strnad et al., 2011). Considering together with the conserved cysteine residue in the type I keratins (e.g. Cys $401^{\mathrm{K} 10}$ ), we suggest that the number of cysteines in keratins have been increased as a result of terrestrial adaptation. It is noteworthy that the number of cysteines were relatively high in lamprey keratins, which may be utilized for keratinized "teeth" (Alibardi and Segalla, 2011) or for thick epidermis with no scales (Elliott, 2011).

\subsection{Relaxation of purifying selection and diversification of keratin genes}

Generally, functional genes are under purifying selection to keep the original function of the protein. In the case of gene duplication, one of the duplicated copies is expected to become free from purifying selection and can acquire a new function, whereas the other copy retains the original function (Ohno, 1970). The relaxation of purifying selection and functional diversification are often discussed in the 
multigene family such as the olfactory or pheromone receptor gene family (e.g., Niimura et al., 2014; Grus and Zhang, 2004). The relaxation of purifying selection can be elucidated from the elevation of the $d_{\mathrm{N}} / d_{\mathrm{S}}$ value, which is caused by the acceleration of non-synonymous substitutions. In the present study, we calculated the $d_{\mathrm{N}} / d_{\mathrm{S}}$ of keratin genes for several clades of interest (Fig. 2; $\mathrm{C}^{\prime}, \mathrm{E}^{\prime}, \mathrm{F}^{\prime}$ and Table 1) to examine the relaxation of purifying selection. We found that the $d_{\mathrm{N}} / d_{\mathrm{S}}$ was elevated in subcluster 3 in reedfish and the "adult epidermal keratin subcluster" in amphibians, implying that the keratin genes were diversified in function. In Vandebergh and Bossuyt (2012), duplication and the expansion of the keratin genes contributed to terrestrial adaptation. Indeed, caecilians and western clawed frogs adapted to terrestrial environments, and reedfish are viable in terrestrial environments (Pace and Gibb, 2011; Sacca and Burggren, 1982). Our analyses suggest that the expansion of the keratin genes and relaxation of purifying selection may have facilitated the epidermal adaptation to the terrestrial environment in these species. In particular, diversification of amphibian adult epidermal keratin subcluster (clade $\mathrm{E}^{\prime}$ and $\mathrm{F}^{\prime}$ ) might be important to terrestrial adaptation. The fish skin consists of three main layers: epidermis, scales and dermis. In contrast, amphibians lost the scales and acquired a stratum corneum, which contains various keratins and is important to prevent skin from water loss (Yokoyama et al., 2018). Thus, we expect that there may be an evolutionary link between the diversification of clade $\mathrm{E}^{\prime}$ and $\mathrm{F}^{\prime}$ keratin genes and the acquisition of stratum corneum.

\section{Conclusion}

In the present study, we revealed that two major keratin gene clusters are shared among Cyclostomata, Chondrichthyes, basal Actinopterygii, and Sarcopterygii (including terrestrial vertebrates), but not in teleost fish. The result suggests that two major clusters originated in the common ancestor of vertebrates and were conserved among most vertebrates, except for teleost fish, in which the clusters were scattered in multiple chromosomes because of whole genome duplication 
(3R). The keratin genes belonging to the adult epidermal subclusters in amphibians originated in the two major clusters that had already existed before the timing of the terrestrial adaptation. The specific cysteine residues conserved among mammalian keratins were also found to be conserved in amphibian keratins, which were specifically expressed in adult epidermis, implying that they may contribute to terrestrial adaptation. We found that the pair of $k r t 18 / k r t 8$ genes in a head-to-head array was conserved in all vertebrates, implying the ancestral and essential function of the keratin pairs in epidermal development. The signatures for the relaxation of purifying selection in keratin gene subclusters in reedfish and amphibians represent the possibility of functional diversification in keratins. Thus, the process of terrestrial adaptation in the vertebrate epidermis may be explained by the series of gene duplications from the ancestral keratin genes inherited from ancient lineages. 


\section{References}

Alibardi, L., 2001. Keratinization in the epidermis of amphibians and the lungfish: Comparison with amniote keratinization. Tissue Cell 33, 439-449. https://doi.org/10.1054/tice.2001.0198

Alibardi, L., Segalla, A., 2011. The Process of Cornification in the Horny Teeth of the Lamprey Involves Proteins in the Keratin Range and Other Keratin-Associated Proteins 50, 416-425.

Altschul, S.F., Gish, W., Miller, W., Myers, E.W., Lipman, D.J., 1990. Basic local alignment search tool. J. Mol. Biol. 215, 403-410. https://doi.org/10.1016/S0022-2836(05)80360-2

Amemiya, C.T., Alföldi, J., Lee, A.P., Fan, S., Philippe, H., Maccallum, I., Braasch, I., Manousaki, T., Schneider, I., Rohner, N., Organ, C., Chalopin, D., Smith, J.J., Robinson, M., Dorrington, R.A., Gerdol, M., Aken, B., Biscotti, M.A., Barucca, M., Baurain, D., Berlin, A.M., Blatch, G.L., Buonocore, F., Burmester, T., Campbell, M.S., Canapa, A., Cannon, J.P., Christoffels, A., De Moro, G., Edkins, A.L., Fan, L., Fausto, A.M., Feiner, N., Forconi, M., Gamieldien, J., Gnerre, S., Gnirke, A., Goldstone, J. V, Haerty, W., Hahn, M.E., Hesse, U., Hoffmann, S., Johnson, J., Karchner, S.I., Kuraku, S., Lara, M., Levin, J.Z., Litman, G.W., Mauceli, E., Miyake, T., Mueller, M.G., Nelson, D.R., Nitsche, A., Olmo, E., Ota, T., Pallavicini, A., Panji, S., Picone, B., Ponting, C.P., Prohaska, S.J., Przybylski, D., Saha, N.R., Ravi, V., Ribeiro, F.J., Sauka-Spengler, T., Scapigliati, G., Searle, S.M.J., Sharpe, T., Simakov, O., Stadler, P.F., Stegeman, J.J., Sumiyama, K., Tabbaa, D., Tafer, H., Turner-Maier, J., van Heusden, P., White, S., Williams, L., Yandell, M., Brinkmann, H., Volff, J.-N., Tabin, C.J., Shubin, N., Schartl, M., Jaffe, D.B., Postlethwait, J.H., Venkatesh, B., Di Palma, F., Lander, E.S., Meyer, A., LindbladToh, K., 2013. The African coelacanth genome provides insights into tetrapod evolution. Nature 496, 311-6. https://doi.org/10.1038/nature12027

Balmer, P., Bauer, A., Pujar, S., McGarvey, K.M., Welle, M., Galichet, A., Müller, E.J., Pruitt, K.D., Leeb, T., Jagannathan, V., 2017. A curated catalog of canine and equine keratin genes. PLoS One 12, e0180359. https://doi.org/10.1371/journal.pone.0180359

Braasch, I., Gehrke, A.R., Smith, J.J., Kawasaki, K., Manousaki, T., Pasquier, J., Amores, A., Desvignes, T., Batzel, P., Catchen, J., Berlin, A.M., Campbell, M.S., Barrell, D., Martin, K.J., Mulley, J.F., Ravi, V., Lee, A.P., Nakamura, T., Chalopin, D., Fan, S., Wcisel, D., Caestro, C., Sydes, J., Beaudry, F.E.G., Sun, Y., Hertel, J., Beam, M.J., Fasold, M., Ishiyama, M., Johnson, J., Kehr, S., Lara, M., Letaw, J.H., Litman, G.W., Litman, R.T., Mikami, M., Ota, T., Saha, N.R., Williams, L., Stadler, P.F., Wang, H., Taylor, J.S., Fontenot, Q., Ferrara, A., Searle, S.M.J., Aken, B., Yandell, M., Schneider, I., Yoder, J.A., Volff, J.N., Meyer, A., Amemiya, C.T., Venkatesh, B., Holland, P.W.H., Guiguen, Y., Bobe, J., Shubin, N.H., Di Palma, F., Alföldi, J., Lindblad-Toh, K., Postlethwait, J.H., 2016. The spotted gar genome illuminates vertebrate evolution and facilitates human-teleost comparisons. Nat. Genet. 48, 427-437. https://doi.org/10.1038/ng.3526

Bunick, C.G., Milstone, L.M., 2017. The X-Ray Crystal Structure of the Keratin 1-Keratin 10 Helix 2B Heterodimer Reveals Molecular Surface Properties and Biochemical Insights into Human 
Skin Disease. J. Invest. Dermatol. 137, 142-150. https://doi.org/10.1016/j.jid.2016.08.018

Cantu, V.A., Sadural, J., Edwards, R., 2019. PRINSEQ++, a multi-threaded tool for fast and efficient quality control and preprocessing of sequencing datasets.

https://doi.org/10.7287/peerj.preprints.27553v1

Chu, P.G., Weiss, L.M., 2002. Keratin expression in human tissues and neoplasms. Histopathology. https://doi.org/10.1046/j.1365-2559.2002.01387.x

Dobin, A., Davis, C.A., Schlesinger, F., Drenkow, J., Zaleski, C., Jha, S., Batut, P., Chaisson, M.,

Gingeras, T.R., 2013. STAR: ultrafast universal RNA-seq aligner. Bioinformatics 29, 15-21.

https://doi.org/10.1093/bioinformatics/bts635

Duprey, P., Morello, D., Vasseur, M., Babinet, C., Condamine, H., Brûlet, P., Jacob, F., 1985.

Expression of the cytokeratin endo A gene during early mouse embryogenesis. Proc. Natl.

Acad. Sci. U. S. A. 82, 8535-8539. https://doi.org/10.1073/pnas.82.24.8535

Ehrlich, F., Fischer, H., Langbein, L., Praetzel-Wunder, S., Ebner, B., Figlak, K., Weissenbacher, A.,

Sipos, W., Tschachler, E., Eckhart, L., 2019. Differential Evolution of the Epidermal Keratin

Cytoskeleton in Terrestrial and Aquatic Mammals. Mol. Biol. Evol. 36, 328-340.

https://doi.org/10.1093/molbev/msy214

Elliott, D.G., 2011. THE SKIN | Functional Morphology of the Integumentary System in Fishes, in:

Encyclopedia of Fish Physiology. Elsevier, pp. 476-488. https://doi.org/10.1016/B978-0-12-

374553-8.00108-8

Grabherr, M.G., Haas, B.J., Yassour, M., Levin, J.Z., Thompson, D.A., Amit, I., Adiconis, X., Fan,

L., Raychowdhury, R., Zeng, Q., Chen, Z., Mauceli, E., Hacohen, N., Gnirke, A., Rhind, N., Di

Palma, F., Birren, B.W., Nusbaum, C., Lindblad-Toh, K., Friedman, N., Regev, A., 2011. Full-

length transcriptome assembly from RNA-Seq data without a reference genome. Nat.

Biotechnol. 29, 644-652. https://doi.org/10.1038/nbt.1883

Grus, W.E., Zhang, J., 2004. Rapid turnover and species-specificity of vomeronasal pheromone

receptor genes in mice and rats. Gene 340, 303-312. https://doi.org/10.1016/j.gene.2004.07.037

Guo, Y., Redmond, C.J., Leacock, K.A., Brovkina, M. V., Ji, S., Jaskula-Ranga, V., Coulombe, P.A., 2020. Keratin 14-dependent disulfides regulate epidermal homeostasis and barrier function via 14-3-3 $\alpha$ and YAP1. Elife 9, 1-24. https://doi.org/10.7554/eLife.53165

Heimroth, R.D., Casadei, E., Salinas, I., 2018. Effects of experimental terrestrialization on the skin mucus proteome of African lungfish (Protopterus dolloi). Front. Immunol. 9.

https://doi.org/10.3389/fimmu.2018.01259

Hellsten, U., Harland, R.M., Gilchrist, M.J., Hendrix, D., Jurka, J., Kapitonov, V., Ovcharenko, I., Putnam, N.H., Shu, S., Taher, L., Blitz, I.L., Blumberg, B., Dichmann, D.S., Dubchak, L., Amaya, E., Detter, J.C., Fletcher, R., Gerhard, D.S., Goodstein, D., Graves, T., Grigoriev, I. V., Grimwood, J., Kawashima, T., Lindquist, E., Lucas, S.M., Mead, P.E., Mitros, T., Ogino, H., Ohta, Y., Poliakov, A. V., Pollet, N., Robert, J., Salamov, A., Sater, A.K., Schmutz, J., Terry, A., Vize, P.D., Warren, W.C., Wells, D., Wills, A., Wilson, R.K., Zimmerman, L.B., Zorn, 
A.M., Grainger, R., Grammer, T., Khokha, M.K., Richardson, P.M., Rokhsar, D.S., 2010. The genome of the western clawed frog xenopus tropicalis. Science (80-. ). 328, 633-636. https://doi.org/10.1126/science.1183670

Hesse, M., Zimek, A., Weber, K., Magin, T.M., 2004. Comprehensive analysis of keratin gene clusters in humans and rodents. Eur. J. Cell Biol. 83, 19-26. https://doi.org/10.1078/0171-933500354

Jacob, J.T., Coulombe, P.A., Kwan, R., Omary, M.B., 2018. Types I and II keratin intermediate filaments. Cold Spring Harb. Perspect. Biol. 10, a018275.

https://doi.org/10.1101/cshperspect.a018275

Katoh, K., Toh, H., 2008. Recent developments in the MAFFT multiple sequence alignment program. Brief. Bioinform. 9, 286-298. https://doi.org/10.1093/bib/bbn013

Kumar, S., Stecher, G., Li, M., Knyaz, C., Tamura, K., 2018. MEGA X: Molecular Evolutionary Genetics Analysis across Computing Platforms. Mol. Biol. Evol. 35, 1547-1549. https://doi.org/10.1093/molbev/msy096

Lee, C., Kim, M., Chung, B.M., Leahy, D.J., Coulombe, P.A., 2012. Structural basis for heteromeric assembly and perinuclear organization of keratin filaments. Nat. Struct. Mol. Biol. 19. https://doi.org/10.1038/nsmb.2330

Liang, Y.C., Wu, P., Lin, G.W., Chen, C.K., Yeh, C.Y., Tsai, S., Yan, J., Jiang, T.X., Lai, Y.C., Huang, D., Cai, M., Choi, R., Widelitz, R.B., Lu, W., Chuong, C.M., 2020. Folding Keratin Gene Clusters during Skin Regional Specification. Dev. Cell 53, 561-576.e9. https://doi.org/10.1016/j.devcel.2020.05.007

Meyer, A., Van de Peer, Y., 2005. From 2R to 3R: evidence for a fish-specific genome duplication (FSGD). BioEssays 27, 937-945. https://doi.org/10.1002/bies.20293

Niimura, Y., Matsui, A., Touhara, K., 2014. Extreme expansion of the olfactory receptor gene repertoire in African elephants and evolutionary dynamics of orthologous gene groups in 13 placental mammals. Genome Res. 24, 1485-1496. https://doi.org/10.1101/gr.169532.113

Ohno, S., 1970. Evolution by Gene Duplication, Evolution by Gene Duplication. Springer Berlin Heidelberg. https://doi.org/10.1007/978-3-642-86659-3

Pace, C.M., Gibb, A.C., 2011. Locomotor behavior across an environmental transition in the ropefish, Erpetoichthys calabaricus. J. Exp. Biol. 214, 530-537. https://doi.org/10.1242/jeb.047902

Sacca, R., Burggren, W., 1982. Oxygen uptake in air and water in the air-breathing reedfish Calamoichthys calabaricus: role of skin, gills and lungs. J. Exp. Biol. 97, 179-186.

Sandilands, A., Sutherland, C., Irvine, A.D., McLean, W.H.I., 2009. Filaggrin in the frontline: Role in skin barrier function and disease. J. Cell Sci. 122, 1285-1294. https://doi.org/10.1242/jcs.033969

Schaffeld, M., Bremer, M., Hunzinger, C., Mark1, J., 2005. Evolution of tissue-specific keratins as deduced from novel cDNA sequences of the lungfish Protopterus aethiopicus. Eur. J. Cell Biol. 


\section{4, 363-377. https://doi.org/10.1016/J.EJCB.2004.12.006}

Schaffeld, M., Haberkamp, M., Schätzlein, S., Neumann, S., Hunzinger, C., 2007. A novel and ancient group of type 1 keratins with members in bichir, sturgeon and gar. Front. Zool. 4. https://doi.org/10.1186/1742-9994-4-16

Schaffeld, M., Schultess, J., 2006. Genes coding for intermediate filament proteins closely related to the hagfish "thread keratins (TK)" $\alpha$ and $\gamma$ also exist in lamprey, teleosts and amphibians. Exp. Cell Res. 312, 1447-1462. https://doi.org/10.1016/j.yexcr.2006.01.005

Schempp, C., Emde, M., Wölfle, U., 2009. Dermatologie im Darwinjahr. Teil 1: Die Evolution der Haut. JDDG - J. Ger. Soc. Dermatology. https://doi.org/10.1111/j.1610-0387.2009.07193.x

Sire, J.-Y., 1995. Ganoine formation in the scales of primitive actinopterygian fishes, lepisosteids and polypterids. Connect. Tissue Res. 33, 213-222.

https://doi.org/10.3109/03008209509017006

Slater, G.S.C., Birney, E., 2005. Automated generation of heuristics for biological sequence comparison. BMC Bioinformatics 6, 31-31. https://doi.org/10.1186/1471-2105-6-31

Stamatakis, A., 2014. RAxML version 8: a tool for phylogenetic analysis and post-analysis of large phylogenies. Bioinformatics 30, 1312-1313. https://doi.org/10.1093/bioinformatics/btu033

Strnad, P., Usachov, V., Debes, C., Grä, F., Parry, D.A.D., Omary Bishr, M., 2011. Unique amino acid signatures that are evolutionarily conserved distinguish simple-type, epidermal and hair keratins. J. Cell Sci. 124, 4221-4232. https://doi.org/10.1242/jcs.089516

Suzuki, H., 2017. FATE: Framework for Annotating Translatable Exons. https://github.com/Hikoyu/FATE

Suzuki, K. ichi T., Suzuki, M., Shigeta, M., Fortriede, J.D., Takahashi, S., Mawaribuchi, S., Yamamoto, T., Taira, M., Fukui, A., 2017. Clustered Xenopus keratin genes: A genomic, transcriptomic, and proteomic analysis. Dev. Biol. 426, 384-392.

https://doi.org/10.1016/j.ydbio.2016.10.018

Szarski, H., 1962. The Origin of the Amphibia. Q. Rev. Biol. 37, 189-241. https://doi.org/10.1086/403656

Takezaki, N., Nishihara, H., 2016. Resolving the phylogenetic position of coelacanth: The closest relative is not always the most appropriate outgroup. Genome Biol. Evol. 8, 1208-1221. https://doi.org/10.1093/gbe/evw071

Torres-Sánchez, M., Creevey, C.J., Kornobis, E., Gower, D.J., Wilkinson, M., San Mauro, D., 2019. Multi-tissue transcriptomes of caecilian amphibians highlight incomplete knowledge of vertebrate gene families. DNA Res. 26, 13-20. https://doi.org/10.1093/dnares/dsy034

Vandebergh, W., Bossuyt, F., 2012. Radiation and Functional Diversification of Alpha Keratins during Early Vertebrate Evolution. Mol. Biol. Evol. 29, 995-1004.

https://doi.org/10.1093/molbev/msr269

Venkatesh, B., Lee, A.P., Ravi, V., Maurya, A.K., Lian, M.M., Swann, J.B., Ohta, Y., Flajnik, M.F., Sutoh, Y., Kasahara, M., Hoon, S., Gangu, V., Roy, S.W., Irimia, M., Korzh, V., Kondrychyn, 
I., Lim, Z.W., Tay, B.H., Tohari, S., Kong, K.W., Ho, S., Lorente-Galdos, B., Quilez, J., Marques-Bonet, T., Raney, B.J., Ingham, P.W., Tay, A., Hillier, L.W., Minx, P., Boehm, T., Wilson, R.K., Brenner, S., Warren, W.C., 2014. Elephant shark genome provides unique insights into gnathostome evolution. Nature 505, 174-179. https://doi.org/10.1038/nature12826

Vera Alvarez, R., Pongor, L.S., Mariño-Ramírez, L., Landsman, D., 2019. TPMCalculator: one-step software to quantify mRNA abundance of genomic features. Bioinformatics 35, 1960-1962. https://doi.org/10.1093/bioinformatics/bty896

Watanabe, Y., Kobayashi, H., Suzuki, K. ichi, Kotani, K., Yoshizato, K., 2001. New epidermal keratin genes from Xenopus laevis: Hormonal and regional regulation of their expression during anuran skin metamorphosis. Biochim. Biophys. Acta - Gene Struct. Expr. 1517, 339-350. https://doi.org/10.1016/S0167-4781(00)00281-5

Watanabe, Y., Tanaka, R., Kobayashi, H., Utoh, R., Suzuki, K.-I., Obara, M., Yoshizato, K., 2002. Metamorphosis-dependent transcriptional regulation ofxak-c, a novelXenopus type I keratin gene. Dev. Dyn. 225, 561-570. https://doi.org/10.1002/dvdy.10196

Yang, Z., 2007. PAML 4: Phylogenetic Analysis by Maximum Likelihood. Mol. Biol. Evol. 24, 1586-1591. https://doi.org/10.1093/molbev/msm088

Yang, Z., 1998. Likelihood ratio tests for detecting positive selection and application to primate lysozyme evolution. Mol. Biol. Evol. 15, 568-573.

https://doi.org/10.1093/oxfordjournals.molbev.a025957

Yokoyama, H., Kudo, N., Todate, M., Shimada, Y., Suzuki, M., Tamura, K., 2018. Skin regeneration of amphibians: A novel model for skin regeneration as adults. Dev. Growth Differ. 60, 316325. https://doi.org/10.1111/dgd.12544

You, L., Chi, J., Huang, S., Yu, T., Huang, G., Feng, Y., Sang, X., Gao, X., Li, T., Yue, Z., Liu, A., Chen, S., Xu, A., 2019. LanceletDB: an integrated genome database for lancelet, comparing domain types and combination in orthologues among lancelet and other species. Database (Oxford). 2019, 1-10. https://doi.org/10.1093/database/baz056

Zimek, A., Weber, K., 2006. The organization of the keratin I and II gene clusters in placental mammals and marsupials show a striking similarity. Eur. J. Cell Biol. 85, 83-89. https://doi.org/10.1016/j.ejcb.2005.10.001

Zimek, A., Weber, K., 2005. Terrestrial vertebrates have two keratin gene clusters; striking differences in teleost fish. Eur. J. Cell Biol. 84, 623-635. https://doi.org/10.1016/j.ejcb.2005.01.007 


\section{Declaration of Competing Interests}

The authors have no conflicts of interest to declare.

\section{Acknowledgments}

We thank Yujiro Kawabe of the Tokyo Institute of Technology for the animal illustration included in Fig. 3. We also thank Zicong Zhang of the Tokyo Institute of Technology for technical assistance during evolutionary analyses.

\section{Funding Sources}

This work was funded by JSPS KAKENHI (17K19422) and an Asahi Glass Foundation grant awarded to M.N. 
bioRxiv preprint doi: https://doi.org/10.1101/2020.05.06.063123; this version posted October 5, 2020. The copyright holder for this preprint (which was not certified by peer review) is the author/funder, who has granted bioRxiv a license to display the preprint in perpetuity. It is made available under aCC-BY-NC 4.0 International license.

\section{Supplementary Data}

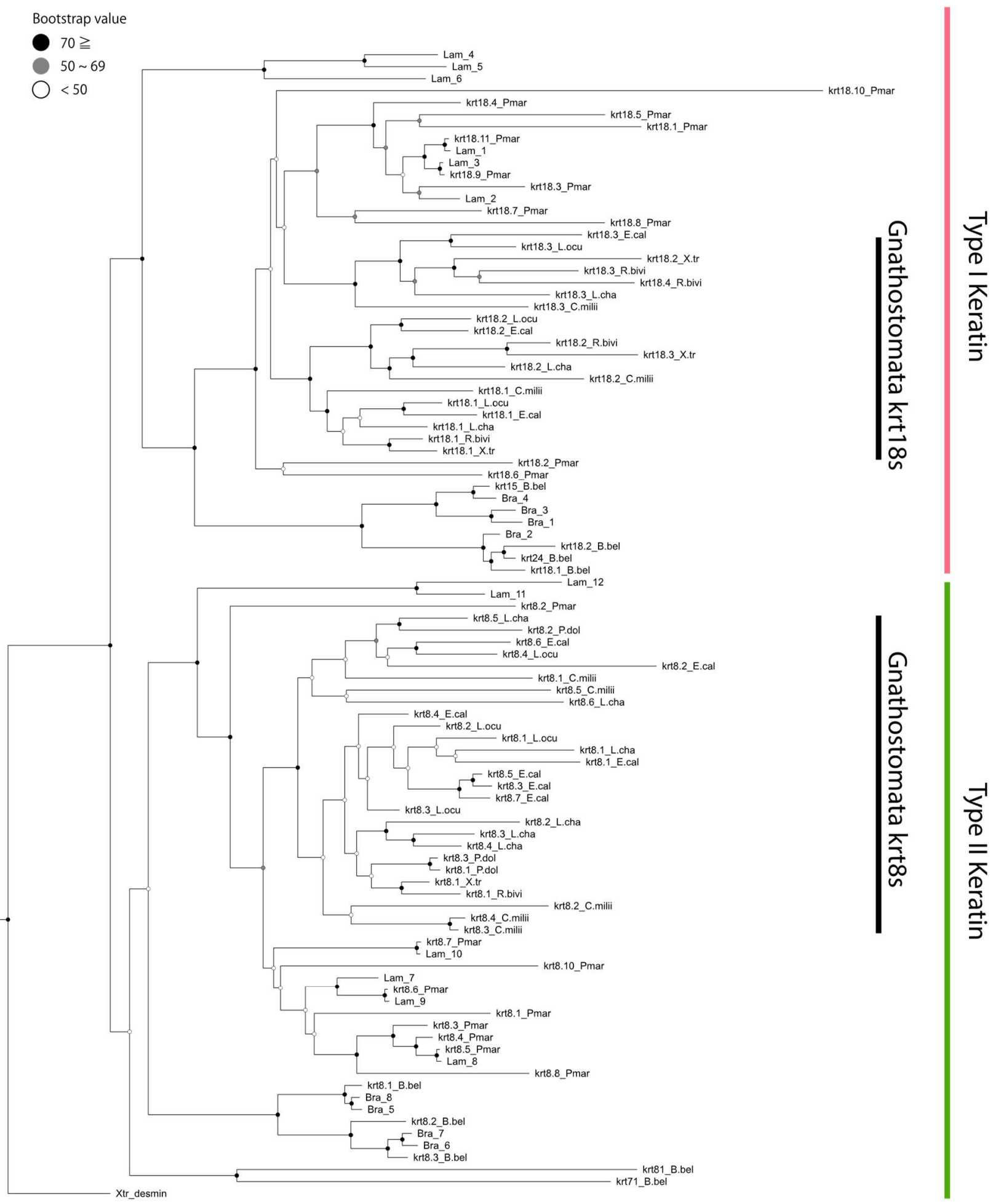


Supplementary Fig. S1. Phylogenetic tree of type I and II keratin genes with focus on the relationships of putative $k r t 18 s$ and $k r t 8 s$ in amphioxus and lamprey. The species included in the analyses are the following: amphioxus (Branchiostoma belcheri; B.bel), lamprey (Petromyzon marinus; P.mar), elephant shark (C. milii; C.milli), reedfish (E. calabaricus; E.cal), spotted gar (L. oculatus; L.ocu), coelacanth (L. chalumnae; L.cha), lungfish (P. dolloi; P.dol), caecilian (R. bivittatum; R.bivi), and western clawed frog (X. tropicalis; X.tr). We also included the keratin gene sequences of other species of amphioxus (B. floridae and B. lanceolatum: Bra) and lamprey (Lampetra fluviatilis: Lam) that were reported in a previous study (Vandebergh and Bossuyt, 2012). Desmin sequence of western clawed frog was used as an outgroup. Black, gray, and white circles on the nodes indicate bootstrap values 70 and over, 50 to 69 , and under 50 , respectively.

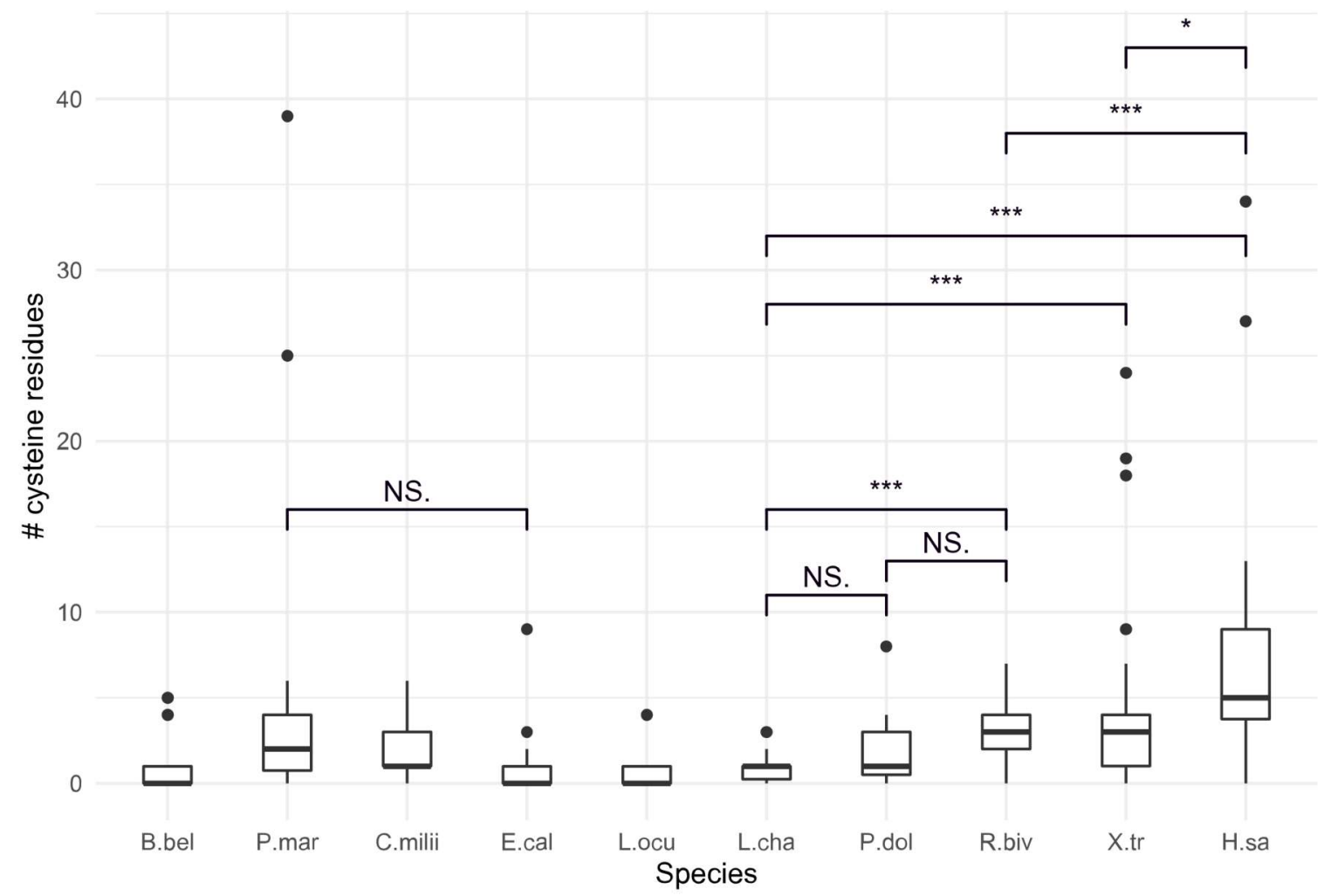

Supplementary Fig. S2. Boxplot of number of cysteine residues in each keratin protein. The species included in the analysis are the following: amphioxus (Branchiostoma belcheri; B.bel), lamprey (Petromyzon marinus; P.mar), elephant shark (C. milii; C.milli), reedfish (E. calabaricus; E.cal), spotted gar (L. oculatus; L.ocu), coelacanth (L. chalumnae; L.cha), lungfish (P. dolloi; P.dol), caecilian (R. bivittatum; R.bivi), western clawed frog (X. tropicalis; X.tr) and human (Homo sapiens; H.sa). Note that hair keratins of human were not included in this analysis. $t$-test was calculated between some species. *,**: $P$-values significant at $<0.05,<0.001$ levels, respectively. 


\begin{tabular}{|c|c|}
\hline & 401 \\
\hline kt10_H.sa & LAETEGRYCVQLSQI \\
\hline ktt14_H.sa & LEETKGRYCMQLAQ I \\
\hline krt17_X.tr & LAETEGRYCVQLSQI \\
\hline ktt12.6_X.tr & LAETEGRF CSQLGQL \\
\hline kt57_X.tr & LAETEGAFCVKLAR I \\
\hline kt53_X.tr & L AETEGRF CMKL SVL \\
\hline krt51_X.tr & LAETEGRFCTKLSH I \\
\hline kt50_X.tr & LAETEARF CMKLSHL \\
\hline kt56_X.tr & VGKTEGSYCRKLSRI \\
\hline krt54_X.tr & LAETEG I YCMKLSR I \\
\hline krt55_X.tr & LAETEGSYCMKLSR I \\
\hline ktt12.2_X.tr & LSETEGRYCLSLSQ I \\
\hline kt24_X.tr & LAETEGNYCVQLSKI \\
\hline krt9.1_X.tr & LAETEGRYCLQLSQL \\
\hline krt9.2_X.tr & LAETEGQYCVKLSH I \\
\hline kt19.2_R.bivi & L AETEGRY CMQL SQ I \\
\hline kt9_R.bivi & LAETEGRYCLQLSQ I \\
\hline kt110.2_R.bivi & LAETEGRF CMD I SKL \\
\hline krt47.3_R.bivi & LAETEGRF CME I SKL \\
\hline kt10.3_R.bivi & L AETEGRYCME I SKL \\
\hline ktt47.4_R.bivi & LAETEGRYCME I SKL \\
\hline ktt10.1_R.bivi & LAETEGRF CVQLGDL \\
\hline kt47.1_R.bivi & FAETEGRYCVQ I AQM \\
\hline kt20_R.bivi & LSEVKAWYSSQLEEV \\
\hline krt20_X.tr & LNN I NAQYAAQL L HM \\
\hline kt13_P.dol & L ADTESRYGTMLQD I \\
\hline kt19.1_L.cha & LAETEASYSAQLHKL \\
\hline kt49.1_L.ocu & VADTEARFSAQMGSL \\
\hline krt49.1_E.cal & LEETKARYAAQLAHL \\
\hline milii & $A R Y G A Q F N Q F$ \\
\hline
\end{tabular}

Supplementary Fig. S3. Alignment of partial amino acid sequences of type I keratins with and without the conserved cysteine residue. The species included in the alignment are the following: elephant shark (C. milii; C.milli), reedfish (E. calabaricus; E.cal), spotted gar (L. oculatus; L.ocu), coelacanth (L. chalumnae; L.cha), lungfish (P. dolloi; P.dol), caecilian (R. bivittatum; R.bivi), western clawed frog (X. tropicalis; X.tr) and human (Homo sapiens; H.sa). Representative keratins without the conserved cysteine residues were also included in the alignment. The number '401' above the alignment indicate the $401^{\text {st }}$ residue of human $k r t 10$.

\section{Supplementary File S1.}

FASTA format files for the amino acid sequences of the keratin gene used in the phylogenetic analyses in Fig. 2.

\section{Supplementary File S2.}

FASTA format files for the nucleotide sequences of the keratin gene used in the selection analyses in Table 1. 


\section{Supplementary File S3.}

FASTA format files for the amino acid sequences of the keratin gene used in the phylogenetic analysis in Supplementary Fig. S1.

\section{Supplementary Table S1.}

Keratin gene information (i.e., ID, location, and orientation) of vertebrates and amphioxus analyzed in this study.

\section{Supplementary Table S2.}

Summary of the expression analyses for the RNA-seq data of Rhinatrema bivittatum and Xenopus tropicalis. 